\title{
Erratum to: Luminescence Monitoring of Temporal Changes and Efficiency of Tissue Optical Clearing by NIR-Excited Upconversion Particles
}

\author{
Marina D. Kozintseva ${ }^{1}$ • Elena K. Volkova ${ }^{1}$ - Julia G. Konyukhova ${ }^{1}$. \\ Igor V. Zabenkov ${ }^{2} \cdot V_{\text {yacheslav I. Kochubey }}{ }^{1,3}$
}

Published online: 9 August 2016

(C) Springer Science+Business Media New York 2016

Erratum to: BioNanoScience

DOI 10.1007/s12668-016-0201-5

The original version of this article unfortunately contained a mistake. The Acknowledgments section in the original publication of "Luminescence monitoring of temporal changes and efficiency of tissue optical clearing by NIR-excited upconversion particles" (Kozintseva MD, Volkova EK, Konyukhova JG, Zabenkov IV, Kochubey VI; 2016; doi: 10.1007/s12668-0160201-5) should correspond to the following item:

"Acknowledgments This research was supported in part in the field of the performance of the measurements of tissue clearing by the grant no. 14-15-00186 from the Russian Science Foundation and in the field of the simulation of the experiments by RF Government contract no. 2014/203, Research no. 1490 "Development of optical methods and instrumentation for measurements and control of structure and dynamics of biological media." The authors grateful to Dr. A.P. Popov (Opto-Electronics and Measurement Techniques Laboratory, University of Oulu, Finland) for kindly providing $\mathrm{Y}_{2} \mathrm{O}_{3}: \mathrm{Yb}$, Er upconversion particles and their spectral characteristics (Figure 1), and to Prof V.V. Tuchin (Saratov State University, Russia) for fruitful discussions."

The online version of the original article can be found at http://dx.doi.org/ 10.1007/s12668-016-0201-5.

Julia G. Konyukhova

yugkon@yandex.ru

1 Saratov State University, 83, Astrakhanskaya st., Saratov 410012,

Russia

2 Razumovskii Saratov State Medical University, 112, Bolshaya

Kazachia st., Saratov 410012, Russia

3 Tomsk State University, 36, Lenin Avenue, Tomsk 634050, Russia 